\title{
Avaliação da atividade antibacteriana e triagem fitoquímica das folhas de Acacia longifolia (Andr.) Willd. (Leguminosae)
}

\author{
Peitz, C.; Cúnico, M.M.; Miguel, O.G.; Miguel, M.D.; Kerber, V.A.* \\ Programa de Pós-Graduação em Ciências Farmacêuticas, \\ Universidade Federal do Paraná, Curitiba, PR.
}

Recebido para publicação em: 09/07/2003 Aceito para publicação em: 17/11/2003

\begin{abstract}
RESUMO: Avaliou-se a atividade antibacteriana de extratos das folhas de Acacia longifolia (Andr.) Willd., através do método da difusão em gel. Os extratos foram incorporados em discos de papel, e foi verificado o efeito sobre o crescimento de bactérias patogênicas ao homem: Staphylococcus aureus (ATCC 6538), Escherichia coli (ATCC 11129) e Pseudomonas aeruginosa (ATCC 9027). Verificou-se que o extrato etanólico bruto, a fração acetato de etila e a fração etanólica remanescente inibiram o crescimento de $S$. aureus, mas não o de E. coli; somente o extrato etanólico bruto inibiu, em menor grau o crescimento de $P$. aeruginosa. A triagem fitoquímica indicou a presença de taninos, leucoantocianidinas, flavonóides e triterpenos/esteróides nas folhas de A. longifolia.
\end{abstract}

Unitermos: Acacia longifolia; Leguminosae; atividade antibacteriana; triagem fitoquímica.

ABSTRACT: Evaluation of the antibacterial activity and phytochemical screening of the leaves of Acacia longifolia (Andr.) Willd., Leguminosae. The antibacterial activity of the extracts of Acacia longifolia (Andr.) Willd. leaves was evaluated by the gel diffusion method. The extracts were incorporated in paper discs and it was verified the effect on the human pathogenic bacteria growth. The tested bacteria were Staphylococcus aureus (ATCC 6538), Escherichia coli (ATCC 11129) and Pseudomonas aeruginosa (ATCC 9027). The crude ethanolic extract, the ethyl acetate and the remained ethanolic fractions showed growth inhibition of $S$. aureus, only the crude ethanilic extract showed, in lower extension, growth inhibition of $P$. aeruginosa and no growth inhibition at all of $E$. coli. The phytochemical screening indicated the presence of tannins, leucoanthocianidins, flavonoids and triterpene/steroids.

Key words: Acacia longifolia; Leguminosae; antibacterial activity; phytochemical screening. 


\section{INTRODUÇÃO}

Acacia longifolia (Andr.) Willd., é uma árvore pequena (4-5 $\mathrm{m}$ de altura) proveniente da Austrália, sendo utilizada como planta ornamental e fixadora de dunas em terrenos íngremes sujeitos à erosão (BURKART, 1979). O estudo fitoquímico das flores desta espécie revelou a presença de flavonóides (MARINE-BETTOLO; FALCO, 1951; KERBER; SILVA, 1993; SILVA, 2001) e de cumarinas (KERBER; SILVA, 1990). Das folhas já foram isolados alcalóides (ROVELLI e VAUGHAN, 1967) e derivados fenólicos (THIEME; KHOGALI, 1975). A avaliação da atividade antibacteriana de extratos obtidos das flores de $A$. longifolia demonstrou ausência de atividade antibacteriana contra cepas de Staphylococcus aureus, S. epidermides e Escherichia coli (SILVA, 2001).

Várias espécies do gênero Acacia têm demonstrado efeito antibacteriano (SOTOHY; ISMAIL; MUELLER, 1995; MUSTAFA; TANIRA; NSANZE, 1999; KHAN; NGASSAPA; MATEE, 2000). Assim, o presente trabalho objetivou estudar o efeito do extrato bruto e de frações obtidas das folhas de $A$. longifolia sobre o crescimento de Staphylococcus aureus, Escherichia coli e Pseudomonas aeruginosa.

\section{MATERIALE MÉTODOS}

\section{Material vegetal}

O material botânico, foi coletado em maio de 2002, no Campus do Setor de Ciências da Saúde, Sede Botânico, da Universidade Federal do Paraná, situado no município de Curitiba, PR. A identificação da espécie foi realizada pelo botânico Gert Hatchbach do Museu Botânico Municipal de Curitiba. Uma exsicata encontra-se depositada no Herbário desse Museu, sob o número de registro MBM-261.856.

\section{Triagem fitoquímica}

Foi realizada com as frações do extrato etanólico bruto, obtidas por partição, conforme descrito no próximo item, e de acordo com a metodologia proposta por Moreira (1979). Os grupos de metabólitos secundários testados foram compostos antociânicos, saponinas, leucoantocianidinas, flavonóides, taninos, antraquinonas, cumarinas, alcalóides e triterpenos/ esteróides.

\section{Obtenção e fracionamento do extrato etanólico bruto}

Para o preparo do extrato etanólico bruto foram utilizadas $250 \mathrm{~g}$ de folhas previamente secas em temperatura ambiente. O material a ser extraído foi dividido em duas porções de 100 e $150 \mathrm{~g}$, as quais foram maceradas com 300 e $400 \mathrm{~mL}$ de etanol, respectivamente. Após, o extrato de menor volume foi filtrado e concentrado em evaporador rotatório até secura (extrato etanólico bruto). O segundo extrato foi concentrado até $70 \mathrm{~mL}$, mantido em geladeira por 24 horas e filtrado, obtendo-se um precipitado. O fracionamento do extrato etanólico filtrado foi realizado por extração seqüencial com solventes de polaridade crescente (hexano, clorofórmio e acetato de etila) até o líquido extrator não apresentar mais coloração. Todas as frações obtidas, inclusive a etanólica remanescente, foram concentradas até secura, em evaporador rotatório. 


\section{Avaliação da atividade antibacteriana}

Para a avaliação da atividade antibacteriana do extrato etanólico bruto e das frações obtidas das folhas de $A$. longifolia, foi utilizado o método da difusão em gel (SMÂNIA et al., 1995; ULUBELEN et al., 2000). Os materiais-teste foram incorporados em discos de papel (diâmetro de $6 \mathrm{~mm}$ ), e a atividade inibitória sobre Staphylococcus aureus (ATCC 6538), Escherichia coli (ATCC 11129) e Pseudomonas aeruginosa (ATCC 9027) foi verificada através da formação de halos de inibição do crescimento ao redor dos discos. O extrato etanólico bruto foi testado em cinco concentrações $(125,250,500,1000$ e $2000 \mu \mathrm{g}$ por disco) e as frações precipitado, hexano, clorofórmio, acetato de etila e etanólica remanescente, na concentração de $1000 \mu \mathrm{g}$ por disco. Foram utilizados discos impregnados com os solventes, como controle de inibição dos solventes, e com cloranfenicol $(30 \mu \mathrm{g} / \mathrm{disco})$, como controle positivo de inibição. Todos os testes foram realizados em triplicata.

\section{RESULTADOS}

Após a incubação com o extrato etanólico bruto, verificou-se a inibição do crescimento de S. aureus ao redor dos discos impregnados com 1000 e $2000 \mu \mathrm{g}$, com halos de 9,3 e 11,3mm, respectivamente. Também foi verificada a formação de halo de inibição de crescimento de $7,5 \mathrm{~mm}$, na concentração de $2000 \mu \mathrm{g}$ do extrato etanólico bruto, quando da incubação com $P$. aeruginosa. Com E. coli não houve inibição do crescimento bacteriano, nas concentrações testadas (Tabela 1).

Tabela 1. Atividade antibacteriana do extrato bruto etanólico de folhas de Acacia longifolia (Andr.) Willd. (Leguminosae)

\begin{tabular}{|c|c|c|c|}
\hline Concentração ${ }^{a}$ & $\begin{array}{c}\text { Staphylococcus } \\
\text { aureus }^{\text {b }}\end{array}$ & Escherichia coli ${ }^{\mathrm{b}}$ & $\begin{array}{l}\text { Pseudomonas } \\
\text { aeruginosa }^{\text {b }}\end{array}$ \\
\hline 125 & 0 & 0 & 0 \\
\hline 250 & 0 & 0 & 0 \\
\hline 500 & 0 & 0 & 0 \\
\hline 1000 & 9,5 & 0 & 0 \\
\hline 2000 & 11,3 & 0 & 7,5 \\
\hline Cloranfenicol 30 & 26,0 & 23 & 13,0 \\
\hline
\end{tabular}

${ }^{a} \mu \mathrm{g}$ por disco; b Halo de inibição em mm;

No ensaio com as frações do precipitado, hexano, clorofórmio, acetato de etila e etanólica remanescente foi verificado que apenas as frações acetato de etila $(13,5 \mathrm{~mm})$ e etanólica remanescente $(9,5 \mathrm{~mm})$ inibiram o crescimento de $S$. aureus, na concentração de $1000 \mu \mathrm{g} / \mathrm{disco}$. O crescimento de $P$. aeruginosa não foi afetado por tais frações (Tabela 2). 
Tabela 2. Atividade antibacteriana das frações obtidas por extração seqüencial do extrato bruto etanólico de folhas de Acacia longifolia (Andr.) Willd. (Leguminosae)

\begin{tabular}{l|c|c}
\multicolumn{1}{c|}{ Frações $^{\text {a }}$} & Staphylococcus aureus $^{\mathrm{b}}$ & Pseudomonas aeruginosa $^{\mathrm{b}}$ \\
\hline Precipitado & 0 & 0 \\
\hline Hexano & 0 & 0 \\
\hline Clorofórmio & 0 & 0 \\
\hline Acetato de etila & 13,5 & 0 \\
\hline Etanólica remanescente & 9,3 & 0 \\
\hline
\end{tabular}

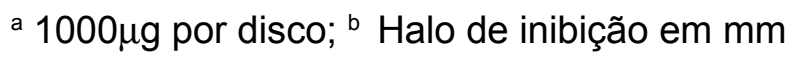

A triagem fitoquímica das frações do extrato etanólico bruto das folhas de $A$. longifolia indicou a presença de triterpenos/esteróides na fração hexânica; de taninos e leucoantocianidinas na fração acetato de etila; e de flavonóides, taninos e saponinas na fração etanólica remanescente.

\section{DISCUSSÃO}

$\mathrm{Na}$ avaliação da atividade antibacteriana do extrato etanólico bruto das folhas de $A$. longifolia e de suas frações ficou demonstrado que o extrato etanólico bruto e as frações acetado de etila e etanólica remanescente apresentaram potencial antibacteriano sobre o crescimento de $S$. aureus, especialmente, a fração acetato de etila, a qual merece ser melhor investigada. O mesmo não aconteceu com relação às outras cepas bacterianas testadas, uma vez que houve menor inibição do crescimento de $P$. aeruginosa e nenhuma inibição do crescimento de $E$. coli. A atividade antibacteriana, detectada para o extrato etanólico bruto e a fração etanólica remanescente, pode ser devida à presença de taninos, uma vez que já foi relatada tal atividade para esse grupo de substâncias (SCALBERT, 1991; SOTOHY et al., 1995) ou, ainda, pela presença de saponinas

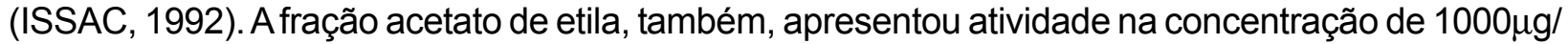
disco, possivelmente, pela presença de taninos (SCALBERT, 1991; SOTOHY et al., 1995). Embora as concentrações de 1000 e $2000 \mu \mathrm{g} /$ disco possam ser consideradas elevadas, extratos brutos e suas frações possuem quantidades elevadas de metabólitos, o que pode diminuir o efeito das substâncias ativas. Desta forma, torna-se interessante a realização de estudos futuros com as substâncias deles isoladas.

\section{AGRADECIMENTOS}

Agradecemos ao botânico Gert Hatschbach do Museu Botânico Municipal da Prefeitura de Curitiba (MBM), pela identificação da espécie vegetal.

Rev. Bras. Farmacogn., V. 13, n. 2, jul.-dez. 2003. 


\section{REFERÊNCIAS BIBLIOGRÁFICAS}

BURKART, A. Flora ilustrada catarinense. As Plantas Leguminosas Mimosoideas. Itajaí: Herbário Barbosa Rodrigues, 1979.

ISSAC, O. Die Ringelblume. Stutgart: Wissenschafliche, 1992 apud SHENKEL, E.P.; GOSMANN, G.; ATHAYDE, M.L. Saponinas. In: SIMÕES, C.O,S; SCHENKEL, E.P.; GOSMANN, G.; MELLO, J.C.P.; MENTZ, L.A.; PETROVICK, P. (Orgs.) Farmacognosia, da planta ao medicamento. Porto Alegre/Florianópolis: Ed. Universidade/Ed. Da UFSC, p. 616, 1999.

KERBER, V.A.; SILVA, G.A.A.B. Cumarinas de Acacia longifolia (Andr) Willd-Leguminosae-Mimosoidae. Revista Brasileira de Farmácia, v.71, n.3, p.64-66, 1990.

KERBER, V.A.; SILVA, G.A.A.B. Flavonoides de Acacia longifolia (Andr) Willd-Leguminosae-Mimosoidae. Revista Brasileira de Farmácia, v.74, n.1, p.16-18, 1993.

KHAN, M.N.; NGASSAPA, O.; MATEE, M.I.N. Antimicrobial activity of Tanzanian chewing sticks against oral pathogenic microbes. Pharmaceutical Biology v.38, n.3, p.235-240, 2000.

MARINI-BETTOLO, G.B.; FALCO, M.R. Ricerche sui pigmenti delle mimosaceae del sud America, Naringenine de una Acacia longifolia del Rio dela Plata. Annales de Chimica, n.41, p.221-226, 1951.

MOREIRA, E.A. Contribuição ao estudo fitoquímico de Lobelia hassleri A. Zahlb e Lobelia stellfeladii R. Braga. Campanulaceae. Tribuna Farmacêutica, v.5, n.9, p.13-39, 1979.

MUSTAFA, N.K.; TANIRA, M.O.M.; NSANZE, H. Antimicrobial activity of Acacia nilotica subspp. nilotica fruit extracts. Pharmaceutical and Pharmacology Communications, v.5, n.9, p.583-586, 1999.

ROVELLI, B.; VAUGHAN, G.N. Alcaloids of Acacia I. N, N-dimethyl-triptamine. Australian Journal of Chemistry, v.20, n.6, p.1299-1300, 1967.

SCALBERT, A. Antimicrobial properties of tannins. Phytochemistry v.30, p.3875-3883, 1991.

SILVA, V.C. Análise dos Flavonóides de Acacia longifolia (Andr.) Willd. Leguminosae-Mimosoideae. Curitiba, 81p. Dissertação (Mestrado) - Programa de Pós-Graduação em Ciências Farmacêuticas - Universidade Federal do Paraná, 2001.

SMÂNIA, A. Jr.; DELLE MONACHE, F.; SMANIA, E.F.A.; GIL, M.L; BENCHERIT, L.C.; CRUZ, F.S. Antibacterial activity of a substance produced by fungus Pycnoporus sanguineus (Fr.) Murr. Journal of Ethnopharmacology, v.45, p.177-181, 1995.

SOTOHY, S.A.; ISMAIL, A.A.; MUELLER, W. Further studies on the antimicrobial properties of some plant materials in relation to their tannin content. Proceedings of the Third Scientific Congress Egyptian Society for Catlle Diseases, v.1, n.1-3, 1995.

THIEME, H.; KHOGALI, A. Über das Vorkommen von Flavonoiden und Gerbstoffen in den Blätter einiger afrikanischer Acacia-Arten. Pharmazie. v.30, n.11, p.736-743, 1975.

ULUBELEN, A.; ÖKSÜZ, S.; BOZOK-JOHANSSON, C.; CELIK, C.; VOELTER, W. Antibacterial diterpenes from the roots of Salvia viridis. Planta Medica, v.66, n.5, p. 458-462, 2000.

*Autor para correspondência:

Prof. Dr. Vitor Alberto Kerber

Programa de Pós Graduação em Ciências Farmacêuticas

Universidade Federal do Paraná

Av. Lothário Meissner, 3400 - Jardim Botânico

80210170 - Curitiba - PR

e-mail: kerber@ufpr.br 